\section{Erratische Schlafzeiten}

Helga Peter ${ }^{1}$ und Thomas Penzel ${ }^{2}$

${ }^{1}$ Marburg, Deutschland

${ }^{2}$ Interdisziplinäres Schlafmedizinisches Zentrum, Charité Universitätsmedizin Berlin, Berlin, Deutschland

\section{Englischer Begriff}

erratic hours

\section{Definition}

Der Begriff bezeichnet regellos variierende Einschlafzeiten nachts und Aufstehzeiten am Morgen (von engl. erratic: regellos, unbeständig). Sie sind ein verbreiteter Auslöser für Ein- und Durchschlafstörungen. Dagegen sind geregelte Zubettgeh- und Aufstehzeiten ein Schlüsselelement für guten Schlaf. Siehe auch $\triangleright$,Schlafhygiene“. 